\title{
Changes in muscle strength after diet-induced weight reduction in adult men with obesity: a prospective study
}

This article was published in the following Dove Press journal: Diabetes, Metabolic Syndrome and Obesity:Targets and Therapy 9 May 2017

Number of times this article has been viewed

\author{
Bokun Kim' \\ Takehiko Tsujimoto ${ }^{2,3}$ \\ Rina So ${ }^{4}$ \\ Xiaoguang Zhao ${ }^{5}$ \\ Sechang $\mathrm{Oh}^{6,7}$ \\ Kiyoji Tanaka ${ }^{2}$
}

'Faculty of Sports Health Care, Inje University, Gyeongsangnamdo, Republic of Korea; ${ }^{2}$ Faculty of Health and Sport Sciences, University of Tsukuba, Ibaraki, ${ }^{3}$ Faculty of Human Sciences, Shimane University, Shimane, ${ }^{4}$ Research Center for OverworkRelated Disorders, National Institute of Occupational Safety and Health, Kawasaki, Kanagawa, ${ }^{5}$ Doctoral Program in Sports Medicine, Graduate School of Comprehensive Human Sciences, ${ }^{6}$ Faculty of Medicine, University of Tsukuba, ${ }^{7}$ The Center of Sports Medicine and Health Sciences, University of Tsukuba Hospital, Tsukuba, Ibaraki, Japan
Correspondence: Sechang Oh Faculty of Medicine, University of Tsukuba, I-I-I Tennodai, Tsukuba, Ibaraki 305-8575, Japan

$\mathrm{Tel} / \mathrm{fax}+8129853329$ ।

Email ohsechang@md.tsukuba.ac.jp
Background and objective: The benefits of weight reduction for musculoskeletal disorders are well understood. Steep declines in muscle mass following considerable weight reduction can decrease muscle strength and, consequently, physical performance. However, only a limited number of studies have examined the changes in muscle mass and strength in the context of interventional weight reduction programs. Thus, we investigated the influence of muscle mass decrease caused by diet-induced weight reduction on muscle strength in obese men.

Methods: A total of 24 men with obesity (body mass index [BMI]: $29.2 \pm 2.6 \mathrm{~kg} / \mathrm{m}^{2}$; age: $52.4 \pm 10.0$ years) attended a 12 -week weight reduction program that implemented dietary restrictions. Each participant underwent assessments of body weight (by a digital scale), body composition (by whole-body dual-energy X-ray absorptiometry [DEXA]), and upper and lower extremity muscle strength (by a hand-held dynamometer and a Biodex System 3 dynamometer, respectively) before and after the program.

Results: The program led to significant reductions of $10.5 \%$ of weight and $6.1 \%$ of lower extremity muscle mass. Similarly, lower extremity muscle strength (measured using a Biodex System 3 dynamometer) was significantly decreased (isometric $60^{\circ}$ peak torque decreased by $10 \%$ and isokinetic $60 \%$ s peak torque decreased by $9.4 \%$ ); however, the level of body weight-normalized lower extremity muscle strength did not significantly change (increased by $+1.2 \%$ and $+1.4 \%$ ). The decrease in muscle strength was related to but did not entirely depend on decrease in muscle mass. Although handgrip strength did not significantly differ $(-2.2 \%)$, the weight-normalized level of this parameter significantly improved (+9.1\%). In addition, decrease in the percentage of whole-body fat mass and increase in the percentage of muscle mass index were observed.

Conclusion: We recommend performing exercise after diet-induced weight reduction to regain muscle mass and strength and improve body weight-normalized lower extremity muscle strength.

Keywords: dietary restriction, muscle mass, muscle strength, obesity, weight reduction

\section{Introduction}

Obesity is associated with a broad range of chronic diseases, including heart disease, hypertension, and diabetes. ${ }^{1}$ In addition to such diseases, obesity can also lead to musculoskeletal disorders (MSDs), such as pain, stiffness, loss of joint mobility, osteoarthritis, epicondylitis, tendinitis, and back pain..$^{2-4}$ To improve the symptoms of MSDs, the American College of Rheumatology (2000) recommends weight reduction, the effectiveness of which has been widely reported. ${ }^{5-7}$

Weight reduction causes decrease not only in fat mass but also in muscle mass: body weight is a major determinant of muscle mass, and lean mass correlates positively with body fat. ${ }^{8,9}$ On the basis of the positive association between muscle mass and strength, a steep decline in muscle mass caused by considerable weight reduction can decrease

Diabetes, Metabolic Syndrome and Obesity:Targets and Therapy 2017:10 187-194

187 (c) (i) (5) $2017 \mathrm{kim}$ et al. This work is published and licensed by Dove Medical Press Limited. The full terms of this license are available at https://www.dovepress.com/terms. (c) ${ }_{\mathrm{BY}}$ NC php and incorporate the Creative Commons Atribution - Non Commercial (unported, v3.0) License (http://creativecommons.org//icenses/by-nc/3.0/). By accessing the work you hereby accept the Terms. Non-commercial uses of the work are permitted without any further permission from Dove Medical Press Limited, provided the work is properly attributed. For permission for commercial use of this work, please see paragraphs 4.2 and 5 of our Terms (https://www.dovepress.com/terms.php). 
muscle strength and, consequently, physical performance..$^{9-11}$ Moreover, low muscle mass and strength may lead to the development of MSDs. Therefore, the decrease in muscle mass and strength that occurs during weight reduction is an important concern.

To date, only a limited number of studies have examined changes in muscle mass and strength in the context of interventional weight reduction programs. ${ }^{12,13}$ In particular, the isolated effects on muscle mass and strength caused by weight reduction following dietary restriction in men with obesity remain unclear. ${ }^{13}$ Therefore, in this study, we investigated how muscle mass reduction caused by diet-induced weight reduction affects muscle strength in men with obesity.

\section{Methods}

\section{Experimental design}

Obese men were enrolled to participate in a 12-week diet restriction program. Data were obtained, and assessments were performed before and after the program. The main outcomes were changes in muscle mass and strength and weight reduction caused by dietary restriction.

\section{Subjects}

Study participants were recruited from communities through advertisements in local newspapers and distributed study flyers. The following inclusion criteria were applied: 1) body mass index (BMI) ${ }^{3} 25 \mathrm{~kg} / \mathrm{m}^{2}$, according to Japanese obesity guidelines; ${ }^{14}$ 2) males between 30 and 64 years of age; 3 ) no intentional change in body weight greater than $5 \%$ in the past 12 months; and 4) no terminal disease, recent muscle injury, or surgery. Subjects were eligible for inclusion in the present study if complete data on body composition and muscle strength from baseline and 12-week follow-up assessments were available. As shown in Figure 1, 33 men fulfilled the inclusion criteria and were included as the study group for enrollment in a 12 -week weight reduction program. We excluded nine participants because they dropped out of the weight reduction program, had incomplete data, or did not participate in the assessments used for the analyses. Consequently, of the initially selected 33 participants, 24 subjects (BMI: $29.2 \mathrm{~kg} / \mathrm{m}^{2}$; age: 52.4 years) were included in the analysis. Each subject provided written informed consent that was approved by the institutional review board (no. 26-118). This study was conducted in accordance with the guidelines proposed in the Declaration of Helsinki, and its protocol was reviewed and approved by the Ethics Committee of the University of Tsukuba, Japan. This study was retrospectively registered at UMIN ID no.: UMIN000024735, November 18, 2016.

\section{Dietary restriction program}

We performed a 12-week dietary restriction program that focused on positively influencing the subjects' diets. This program was based on the Four-Food-Group Point Method, ${ }^{15}$ and each group-based instructional class consisted of a dietary lecture and small interactive group session lasting 90 minutes. The classes were held eight times during the 12-week period. The Four-Food-Group Point Method divides

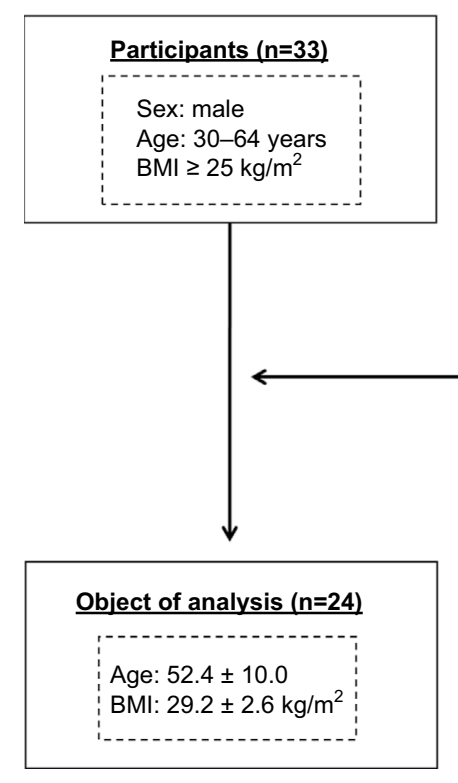

Figure I Flow chart of participant recruitment. Abbreviation: BMI, body mass index. 
a diet into the following four food groups based on nutritional content: group 1 (dairy products and eggs), group 2 (beans, fish, and meat), group 3 (fruits and vegetables), and group 4 (sugar and grains). For nutrient balance calculations and measurements of energy intake, all foods were portioned into $80 \mathrm{kcal}$ servings, and each portion was regarded as 1 point. For each meal, the subjects were instructed to select $1,2,1$, and 3 points of diverse foods from food groups 1, 2, 3 , and 4, respectively, to consume a well-balanced daily diet. Accordingly, the subjects ingested $\sim 21$ points of food per day, corresponding to $1,680 \mathrm{kcal} / \mathrm{d}$. The subjects maintained a daily food diary, in which they recorded all the food that they consumed. During each class, the dieticians reviewed the subjects' diaries and provided them with individualized feedback regarding their energy intake and nutritional balance. Total energy intake $(\mathrm{kcal} / \mathrm{d})$ and the intake amounts $(\mathrm{g} / \mathrm{d})$ of each nutrient (carbohydrate, protein, and fat) were assessed before and at the end of the dietary restriction program using a 3-day weighed dietary records method conducted by a skilled dietitian.

\section{Anthropometry and body composition}

Height was measured to the nearest $0.1 \mathrm{~cm}$ using a wallmounted stadiometer (YG-200; Yagami, Nagoya, Japan), and body weight was measured to the nearest $0.1 \mathrm{~kg}$ using a digital scale with the subject in light clothing and without shoes (TBF-551; Tanita, Tokyo, Japan). BMI was calculated as weight $(\mathrm{kg})$ divided by height $(\mathrm{m})$ squared. Body composition was assessed using whole-body dual-energy X-ray absorptiometry (DEXA; QDR 4500; Hologic Inc., Bedford, MA, USA). The subjects were placed in a supine position with their arms against the sides of their body. Hologic software was used to estimate fat, lean, and bone tissue masses (kg). Extended analyses were performed to obtain separate fat, lean, and bone tissue masses for the arms, legs, and trunk. Visser et $\mathrm{a}^{16}$ reported that lean mass, excluding bone mineral content, is a valid representation of skeletal muscle mass in the extremities. We calculated the appendicular skeletal muscle mass of each subject as the sum of the lean masses, excluding the bone mineral content, of the upper and lower extremities. A height-adjusted index was then calculated by dividing a subject's appendicular skeletal muscle mass in kilogram by the square of their height in meter $\left(\mathrm{m}^{2}\right) \cdot{ }^{17-19} \mathrm{We}$ defined the height-adjusted appendicular skeletal muscle index as the skeletal muscle mass index (SMI). The percentage of muscle mass index (\% MMI) was calculated by dividing each subject's appendicular skeletal muscle mass $(\mathrm{kg})$ by their body weight and multiplying the result by $100 \% .{ }^{20}$

\section{Muscle strength}

\section{Handgrip strength}

Subjects gripped a dynamometer (Grip-D, T.K.K. 5401; Takei Scientific Instruments, Tokyo, Japan) alternately in each hand with maximum effort while lowering the arm naturally to the side of the body. ${ }^{21}$ The assessment was executed twice for each hand, and the best result was recorded as the handgrip strength per hand. Handgrip strength was expressed as absolute and body weight-normalized values.

\section{Knee extensor strength}

Isometric and isokinetic knee extensor strength was assessed using a Biodex System 3 dynamometer (Biodex Medical Systems, Shirley, NY, USA). The subjects performed warmup and cool-down exercises with experienced staff before and after the tests to prevent injury and muscular pain. A 3-minute rest period was allowed between the isometric and isokinetic assessments. The subjects were seated in the Biodex System 3 dynamometer and tightly secured using chest, pelvic, and thigh straps, with their backs supported and their hips flexed at $120^{\circ}$. The axis of rotation of the knee and the Biodex System 3 dynamometer were precisely aligned visually before each test. The knee was extended to $60^{\circ}$ for the isometric assessment (IMT60) because this angle provides nearly optimal quadriceps muscle length to produce maximal force. ${ }^{13}$ Isokinetic muscle strength was assessed at an angular velocity of $60 \%$ s (IKT60). The protocol for the isometric assessment consisted of three maximal extension efforts, each lasting 3 seconds, with intervening 15 -second pauses. The isokinetic assessment was composed of three maximal extensions at an angular velocity of $60 \%$, which is widely used to evaluate isokinetic muscle strength. The highest muscular force output at any moment during the assessment was defined as the peak torque (PTQ) and was reported as absolute values $(\mathrm{Nm})$ and body weight-normalized $(\mathrm{Nm} / \mathrm{kg})$ PTQ. The amount of work accomplished during an entire assessment was defined as the total work and is reported as an absolute value $(\mathrm{J})$, whereas the average of the total work divided by time defined the average power, which is also reported as an absolute value (W). The peak torque in the isometric assessment was used to evaluate static maximum muscle strength; the peak torque in the isokinetic assessment was used to evaluate dynamic maximum muscle strength; the amount of work performed during the isokinetic assessment was used to evaluate dynamic muscle endurance; and the average power in the isokinetic assessment was used to evaluate dynamic muscle power. Every assessment was performed on each leg, and the average strength of both legs was 
calculated to determine the lower extremity muscle strength. These methods have been previously described in detail. ${ }^{10}$

\section{Statistical analysis}

Statistical analysis was performed using SPSS software, version 20.0 (IBM Inc., Armonk, NY, USA). Data are presented as the mean values \pm standard deviation. The Wilcoxon signed-rank test was used to assess differences between the variables before and after the program. Partial correlation analysis was performed to remove the age effect between variables before the weight reduction program and between changes in variables from before the weight reduction program to the follow-up after the program. To evaluate whether muscle mass change correlated with body weight change and whether muscle strength change correlated with muscle mass change, partial correlation analysis was performed to remove the age effect. Statistical significance was set at $P<0.05$.

\section{Results}

\section{Total energy intake before and after the dietary restriction program}

Table 1 presents the total energy intake before and after the 12-week dietary restriction program. Total energy intake $(-28.5 \%, P<0.01)$, carbohydrate intake $(-26.9 \%, P<0.01)$, protein intake $(-13.1 \%, P<0.05)$, and fat $(-31.3 \%, P<0.01)$ intake were all significantly reduced after the program.

\section{Changes in body weight, body composition, and muscle mass and strength caused by dietary restriction}

Table 2 shows the characteristics of the subjects before and after the 12-week dietary restriction program. After the program, the following significant changes were observed in body weight, body composition, and muscle strength. Body weight decreased by an average of $10.5 \%(P<0.01)$. The percentages of whole body fat mass and leg muscle mass, as well as the SMI, were significantly decreased (by $-14.7 \%$, $-6.1 \%$, and $-5.4 \%$, respectively; $P<0.01)$. Static maximal muscle strength $(-10.0 \%$ at IMT60 PTQ, $P<0.01)$, dynamic maximal muscle strength $(-9.4 \%$ at IKT60 PTQ, $P<0.01)$, dynamic muscle endurance $(-6.9 \%$ at IKT60 TW, $P<0.01)$, and dynamic muscle power $(-7.6 \%$ at IKT60 AP, $P<0.01)$ declined significantly, and \% MMI $(+6.3 \% ; P<0.01)$ and handgrip strength per body weight $(+9.1 \% ; P<0.01)$ significantly improved at week 12 . However, arm muscle mass, handgrip strength, and body weight-normalized static and dynamic maximal muscle strength $(-3.0 \%,-2.2 \%,-1.2 \%$ at IKT60 PTQ and $-1.4 \%$ at IKT60 PTQ, respectively) did not change significantly.

\section{Relationship between leg muscle mass, body weight, and leg muscle strength}

Table 3 presents partial correlation coefficients adjusted for age. We only investigated correlations between body weight, leg muscle mass, and leg muscle strength because there were no significant changes in arm muscle mass or handgrip strength after the dietary restriction program. The results indicate that every measurement of absolute change in leg muscle strength was moderately to highly related to leg muscle mass and that absolute change in leg muscle mass was related to body weight before and after the dietary restriction program. Body weight-normalized muscle strength was not significantly associated with body weight or leg muscle mass before or after the dietary restriction program. We also found that the rates of change in leg muscle mass were not absolutely dependent on the rates of change in body weight and that the rates of change in leg muscle strength were not absolutely dependent on the rates of change in leg muscle mass, as summarized in Table 4.

\section{Discussion}

The primary findings of this study were that a 12 -week dietary restriction program led to significant reductions in both weight and lower extremity muscle mass. Accordingly, lower extremity muscle strength (measured using a Biodex System 3 dynamometer) significantly decreased during the program. However, the level of body weight-normalized lower extremity muscle strength did not significantly change. Although handgrip strength did not differ significantly, body weight-normalized handgrip strength significantly improved after the program. In addition, decrease in the percentage of whole-body fat mass and increase in \% MMI were observed

Table I Total energy intake before and after a I2-week dietary restriction program

\begin{tabular}{|c|c|c|c|c|}
\hline Parameter & Pre (range) & Post (range) & Change $(95 \% \mathrm{Cl})$ & $P$ \\
\hline Total energy intake, kcal/d & $2,228.8 \pm 570.6(1,385.0,3,546.0)$ & $1,593.9 \pm 198.3(1,187.0,2,013.0)$ & $-634.9 \pm 559.8(-87 \mid .3,-398.5)$ & $<0.01$ \\
\hline Carbohydrate, g/d & $279.5 \pm 92.5(133.6,566.8)$ & $204.4 \pm 27.0(144.9,261.1)$ & $-75.1 \pm 88.9(-112.6,-37.6)$ & $<0.01$ \\
\hline Protein, g/d & $83.2 \pm 17.9(49.2,119.0)$ & $72.3 \pm 14.6(42.6,103.1)$ & $-10.9 \pm 19.7(-19.3,-2.6)$ & $<0.05$ \\
\hline Fat, g/d & $68.6 \pm 24.4(24.8,132.0)$ & $47.2 \pm 10.6(28.8,74.8)$ & $-21.5 \pm 27.7(-33.2,-9.78)$ & $<0.01$ \\
\hline
\end{tabular}

Note: Values represent the mean \pm standard deviation (range). 
Table 2 Characteristics of participants before and after a 12-week dietary modification program

\begin{tabular}{|c|c|c|c|c|}
\hline Parameter & Pre (range) & Post (range) & Change $(95 \% \mathrm{Cl})$ & $P$ \\
\hline Age, year & $52.4 \pm 10.0(32.0,64.0)$ & & & \\
\hline Height, cm & $168.8 \pm 6.4(|56|,. \mid 84.6)$ & & & \\
\hline Weight, kg & $83.4 \pm \mathrm{II} .0(70.4,102.7)$ & $73.2 \pm 14.3(61.7,97.2)$ & $-8.8 \pm 3.6(-10.3,-7.2)$ & $<0.01$ \\
\hline Body mass index, $\mathrm{kg} / \mathrm{m}^{2}$ & $29.2 \pm 2.6(25.7,34.7)$ & $26.1 \pm 2.6(22.5,32.7)$ & $-3.1 \pm 1.3(-3.6,-2.5)$ & $<0.01$ \\
\hline$\% \mathrm{WF}, \mathrm{kg}$ & $25.1 \pm 4.0(18.9,33.4)$ & $21.5 \pm 4.9(14.3,32.4)$ & $-3.7 \pm 2.3(-4.7,-2.7)$ & $<0.01$ \\
\hline Arm muscle mass, $\mathrm{kg}$ & $6.6 \pm 1.0(5.1,9.2)$ & $6.4 \pm 1.1(4.7,9.1)$ & $-0.2 \pm 0.5(-0.4,0.1)$ & 0.10 \\
\hline Leg muscle mass, kg & $19.6 \pm 3.1(15.9,26.4)$ & $18.4 \pm 3.1(14.3,25.3)$ & $-1.2 \pm 0.7(-1.5,-0.9)$ & $<0.01$ \\
\hline SMI, kg & $9.2 \pm 0.9(7.8,11.2)$ & $8.7 \pm 0.9(7.0,10.8)$ & $-0.5 \pm 0.3(-0.6,-0.4)$ & $<0.01$ \\
\hline$\% \mathrm{MMI}, \%$ & $31.5 \pm 3.0(25.3,37.2)$ & $33.5 \pm 3.9(26.9,40.2)$ & $2.0 \pm 1.6(1.3,2.6)$ & $<0.01$ \\
\hline HGS & $45.3 \pm 6.1(34.5,56.6)$ & $44.2 \pm 5.8(35.9,57.6)$ & $-1.0 \pm 3.2(-2.4,0.3)$ & 0.12 \\
\hline HGS/BW, kg & $0.55 \pm 0.08(0.44,0.73)$ & $0.64 \pm 0.22(0.43,0.77)$ & $0.05 \pm 0.05(0.03,0.07)$ & $<0.01$ \\
\hline IMT60 PTQ, Nm & $2 \mid 4.1 \pm 53.8(\mid 36.2,347.9)$ & $192.6 \pm 43.3(116.0,322.0)$ & $-21.5 \pm 30.4(-34.3,-8.7)$ & $<0.01$ \\
\hline IMT60 PTQ/BW, Nm/kg & $2.56 \pm 0.5 \mathrm{I}(1.79,3.52)$ & $2.77 \pm 1.07(1.61,3.58)$ & $0.03 \pm 0.36(-0.12,0.19)$ & 0.36 \\
\hline IKT60 PTQ, Nm & $177.8 \pm 53.2(101.3,347.9)$ & $|6| . \mid \pm 46.6(73.8,281.8)$ & $-16.7 \pm 14.9(-23.0,-10.3)$ & $<0.01$ \\
\hline IKT60 PTQ/BW, Nm/kg & $2.13 \pm 0.50(1.27 .3 .43)$ & $2.29 \pm 0.88(1.02,3.14)$ & $0.03 \pm 0.19(-0.04,0.11)$ & 0.36 \\
\hline IKT60 TW, J & $496.5 \pm 136.8(272.1,838.4)$ & $462.1 \pm 127.3(2 \mid 3.6,793.4)$ & $-34.3 \pm 35.8(-49.5,-19.2)$ & $<0.01$ \\
\hline IKT60 AP, W & $110.8 \pm 34.8(62.0,209.1)$ & $102.4 \pm 30.8(47.0,188.3)$ & $-8.4 \pm 8.7(-12.0,-4.7)$ & $<0.01$ \\
\hline
\end{tabular}

Note: Values represent the mean \pm standard deviation (range).

Abbreviations: HGS, handgrip strength; HGS/BW, handgrip strength/body weight; IKT60 AP, isokinetic 60 average power; IKT60 PTQ, isokinetic 60 peak torque; IKT60 PTQ/BW, isokinetic 60 peak torque/body weight; IMT60 PTQ, Isometric60 peak torque; IMT60 PTQ/BW, isometric 60 peak torque/body weight; IKT60 TW, isokinetic 60 total work; \% MMI, percentage of muscle mass index; SMI, skeletal muscle mass index; \% WF, percentage of whole-body fat mass.

Table 3 Partial correlation coefficients adjusted for age ${ }^{a}$

\begin{tabular}{|c|c|c|c|c|c|c|c|c|}
\hline & Weight & $\begin{array}{l}\text { Leg muscle } \\
\text { mass }\end{array}$ & $\begin{array}{l}\text { IMT60 PTQ, } \\
\text { Nm }\end{array}$ & $\begin{array}{l}\text { IMT60 PTQ/ } \\
\text { BW, Nm/kg }\end{array}$ & $\begin{array}{l}\text { IKT60 } \\
\text { PTQ, Nm }\end{array}$ & $\begin{array}{l}\text { IKT60 PTQ/ } \\
\text { BW, Nm/kg }\end{array}$ & $\begin{array}{l}\text { IKT60 } \\
\text { TW, J }\end{array}$ & $\begin{array}{l}\text { IKT60 AP, } \\
\text { W }\end{array}$ \\
\hline Weight, kg & & $0.47 *$ & 0.07 & $-0.75 * *$ & 0.11 & $-0.72 * *$ & 0.09 & 0.12 \\
\hline Leg muscle mass, kg & $0.63 * *$ & & $0.63 * *$ & 0.07 & $0.64 * *$ & 0.08 & $0.67 * *$ & $0.61 * *$ \\
\hline IMT60 PTQ, Nm & 0.33 & $0.70^{*}$ & & $0.47 *$ & $0.86 * *$ & $0.43 *$ & $0.86 * *$ & $0.87 * *$ \\
\hline IMT60 PTQ/BW, Nm/kg & -0.29 & 0.29 & $0.80 * *$ & & $0.42 *$ & $0.97 * *$ & $0.42 *$ & 0.40 \\
\hline IKT60 PTQ, Nm & 0.23 & $0.58 * *$ & $0.80 * *$ & $0.64 * *$ & & $0.60 *$ & $0.97 * *$ & $0.98 * *$ \\
\hline IKT60 PTQ/BW, Nm/kg & -0.33 & 0.20 & $0.61 * *$ & $0.82 * *$ & $0.83 * *$ & & $0.49 *$ & $0.47 *$ \\
\hline IKT60 TW, J & 0.22 & $0.68 * *$ & $0.82 * *$ & $0.68 * *$ & $0.92 * *$ & $0.77^{* *}$ & & $0.97 * *$ \\
\hline IKT60 AP, W & 0.23 & $0.62 * *$ & $0.80 * *$ & $0.67 * *$ & $0.96 * *$ & $0.8 I^{* *}$ & $0.95 * *$ & \\
\hline
\end{tabular}

Notes: alues in the lower left half of the table represent correlations between variables before the weight loss program; values in the right half (boldface) of the table represent correlations between changes in variables after the weight loss program. $* P<0.05$. $* * P<0.01$.

Abbreviations: IKT60 AP, isokinetic 60 average power; IKT60 PTQ, isokinetic 60 peak torque; IKT60 PTQ/BW, isokinetic 60 peak torque/body weight; IKT60 TW, isokinetic 60 total work; IMT60 PTQ, isometric 60 peak torque; IMT60 PTQ/BW, isometric 60 peak torque/body weight.

Table 4 Correlations between the rates of change in lower extremity muscle mass and body weight and lower extremity muscle strength adjusted for age

\begin{tabular}{|c|c|c|c|c|c|}
\hline \multicolumn{6}{|c|}{ Rates of change in lower extremity muscle mass } \\
\hline & $\begin{array}{l}\text { Rate of change } \\
\text { in body weight }\end{array}$ & $\begin{array}{l}\text { Rate of change } \\
\text { in IMT60 PTQ }\end{array}$ & $\begin{array}{l}\text { Rate of change } \\
\text { in IKT60 PTQ }\end{array}$ & $\begin{array}{l}\text { Rate of change } \\
\text { in IKT } 60 \mathrm{TW}\end{array}$ & $\begin{array}{l}\text { Rate of change } \\
\text { in IKT60 AP }\end{array}$ \\
\hline & & & $-6.0 \pm 3.6 \%$ & & \\
\hline & $-10.5 \pm 4.1 \%$ & $-8.7 \pm 12.5 \%$ & $-9.3 \pm 7.6 \%$ & $-6.8 \pm 7.7 \%$ & $-7.2 \pm 8.2 \%$ \\
\hline$R^{2}$ & 0.03 & 0.03 & 0.06 & 0.11 & 0.01 \\
\hline$P$ & $0.4 I$ & 0.46 & 0.25 & 0.12 & 0.84 \\
\hline
\end{tabular}

Note: Values represent the mean \pm standard deviation.

Abbreviations: IMT60 PTQ, isometric 60 peak torque; IKT60 PTQ, isokinetic 60 peak torque; IKT60 TW, isokinetic 60 total work; IKT60 AP, isokinetic 60 average power.

(Table 2). Although the augmentation of $\%$ MMI and reduction in the percentage of whole-body fat mass are beneficial for obese men, low muscle mass and strength are also related to the occurrence of MSDs after weight reduction. Consequently, a countermeasure is necessary to regain muscle mass and strength and improve body weight-normalized lower extremity muscle strength after diet-induced weight reduction.

At an average weight reduction of $10.5 \%$, the percentage of whole-body fat mass $(-14.7 \%)$ and the SMI (-5.4\%) both significantly decreased (Table 2). Because body weight is a 
major determinant of muscle mass, and lean mass is positively related to body fat, these results are reasonable. ${ }^{8,22}$ However, the results for lower and upper extremity muscle mass differed. Previous studies have indicated that a heavy body weight, such as in adults with obesity, serves as an exercise training stimulus to gain muscle mass and, accordingly, to increase muscle strength. ${ }^{23-25}$ In particular, people with obesity carry extra weight, which influences the strength of their lower extremities more than their upper extremities. ${ }^{26}$ Consequently, as body weight is reduced, the training stimulus created by body weight in the lower extremities declines, whereas the upper extremities are not greatly affected by the weight reduction. ${ }^{24}$ These relationships explain why muscle mass and strength in the upper extremities were maintained, despite the decrease in lower extremity muscle mass and strength in this study.

Obese men are recommended to decrease their percentage of whole-body fat mass and increase their \% MMI because excessive body fat is a physical burden on the musculoskeletal system, which is sustained by muscle mass. The decrease in whole-body fat mass $(-14.7 \%, P<0.01)$ and $\%$ MMI $(+6.3 \%$, $P<0.01)$ had positive effects on the musculoskeletal system. However, low muscle mass and strength also contribute to the incidence of MSDs after weight reduction. Kim et a ${ }^{27}$ reported that the preservation of muscle mass and strength in the femoral muscle is particularly important after weight reduction because the incidence of MSDs is greatest in the knee joints, which are supported and controlled by femoral muscle mass and strength. Consequently, it is essential to decrease fat mass while diminishing the decrease in muscle mass and strength to prevent or improve obesity-related MSDs.

Our previous study ${ }^{20}$ demonstrated that a weight reduction program consisting of dietary restriction and exercise led to an average weight reduction of $-14.1 \%(P<0.01)$, and this weight reduction was accompanied by significant decrease in lower extremity muscle mass $(-7.2 \% ; P<0.01)$, static maximal muscle strength $(-3.0 \%$ at IMT60 PTQ; $P<0.05)$, and dynamic maximal muscle strength $(-4.8 \%$ at IKT60 PTQ; $P<0.01)$ as well as a significant increase in lower extremity muscle strength per body weight $(+12.9 \%$ at IMT60 PTQ and $+10.9 \%$ at IKT60 PTQ; $P<0.01$ for both) ${ }^{10}$ In the present study, the average weight reduction of $-10.5 \%(P<0.01)$ obtained through dietary restriction triggered decrease in lower extremity muscle mass $(-6.0 \% ; P<0.01)$ and static and dynamic lower extremity muscle strength $(-8.7 \%$ at IMT60 PTQ and $-9.3 \%$ at IKT60 PTQ; $P<0.01$ for both). Lower extremity muscle mass and strength naturally decrease under conditions involving considerable weight reduction. However, compared with our previous study, the rates of decline in lower extremity muscle mass and strength were relatively greater in the present study, and lower extremity muscle strength per body weight did not significantly increase. Assessing absolute muscle strength is the simplest method of evaluating muscle strength, while assessing body weight-normalized muscle strength may be more relevant for identifying functional impairment. ${ }^{28,29}$ Recently, the importance of relative muscle strength has attracted attention. Chomentowski et $\mathrm{al}^{30}$ and Yoshimura et $\mathrm{al}^{31}$ reported that engaging in exercise during dietary restriction helps preserve muscle mass during weight reduction. Based on these reports and the findings of our previous and present studies, engaging in exercise along with dietary restriction is expected to yield significant improvements in body weightnormalized lower extremity muscle strength. However, prescribing exercise to individuals with obesity requires a careful approach that should account for mechanical factors related to the joints. ${ }^{13,32,33}$ Accordingly, performing exercise after completing diet-induced weight reduction is recommended to regain muscle mass and strength and improve body weight-normalized lower extremity muscle strength.

On the basis of the findings reported in Table 3 , it seems clear that changes in leg muscle strength are derived from changes in leg muscle mass and that leg muscle strength is directly proportional to leg muscle mass. However, this association between changes in muscle mass and changes in strength implies that changes in other factors that influence muscle strength also affect muscle mass (Table 4). It has long been thought that changes in muscle strength stem from changes in muscle mass and that muscle strength is directly proportional to muscle mass. ${ }^{34,35}$ In recent years, many studies have reported that changes in muscle strength are not directly proportional to changes in muscle mass; in fact, changes in muscle mass explain only $5 \%$ of the overall change in muscle strength. ${ }^{26}$ Individuals who gain lean mass do not become stronger, which is not unexpected. ${ }^{36}$ The resulting relationships between rates of decrease in muscle mass and muscle strength and weight reduction are in accordance with recent reports. Barbat-Artigas et a ${ }^{28}$ suggested a few factors that could contribute to this discrepancy, including obesity, physical activity, sex hormones, and fibrosis. To date, however, no clear evidence has been presented to explain the discrepancy between muscle mass and strength.

The present study has some limitations. First, the sample size may not have been sufficiently large to draw robust conclusions. However, the $10.5 \%$ weight reduction at the expense of the $6 \%$ decrease in leg muscle mass is highly consistent with the results of an existing report in which a $13 \%$ weight reduction resulted in a $4.6 \%$ decrease in lower extremity muscle mass. ${ }^{13}$ Thus, it is unlikely that the sample 
size affected the results in this study. Second, the subjects' levels of physical activity were not monitored over the 12-week weight reduction program. However, we did encourage the subjects to maintain their habitual levels of physical activity during the weight reduction period. Third, we cannot precisely explain why the change in muscle strength was out of sync with the change in muscle mass after weight reduction. This finding must be further investigated.

\section{Conclusion}

Weight reduction accomplished via dietary restriction induced independent losses in lower extremity muscle mass and strength as well as decrease in SMI. Although the weight reduction observed in this study had positive effects, i.e., decrease in the percentage of whole-body fat mass and increase in $\% \mathrm{MMI}$, it did not have positive effects on body weight-normalized lower extremity muscle strength. Based on these results, we recommend performing exercise after diet-induced weight reduction to regain muscle mass and strength and improve body weight-normalized lower extremity muscle strength.

\section{Acknowledgments}

We thank all the study participants and staff for their assistance. This work was supported in part by Grants-in-Aid for Scientific Research from the Ministry of Education, Culture, Sports, Science and Technology, Japan (no. 2604307).

\section{Disclosure}

The authors report no conflicts of interest in this work.

\section{References}

1. WHO Regional Office for the Western Pacific. Obesity in the Pacific: Too Big to Ignore. Nouméa, New Caledonia: WHO; 2002.

2. Vincent HK, Lamb KM, Day TI, Tillman SM, Vincent KR, George SZ. Morbid obesity is associated with fear of movement and lower quality of life in patients with knee pain-related diagnoses. $P M R$. 2010; 2(8):713-722.

3. Vincent HK, Heywood K, Connelly J, Hurley RW. Obesity and weight loss in the treatment and prevention of osteoarthritis. PM R. 2012; 4(5):S59-S67.

4. WHO. The Burden of Musculoskeletal Disease at the Start of the New Millennium. Geneva, Switzerland: WHO; 2003.

5. Recommendations for the medical management of osteoarthritis of the hip and knee: 2000 update. American College of Rheumatology Subcommittee on Osteoarthritis Guidelines. Arthritis Rheum. 2000;43(9):1905-1915.

6. Coggon D, Reading I, Croft P, McLaren M, Barrett D, Cooper C. Knee osteoarthritis and obesity. Int J Obes Relat Metab Disord. 2001; 25(5):622-627.

7. Christensen R, Bartels EM, Astrup A, Bliddal H. Effect of weight reduction in obese patients diagnosed with knee osteoarthritis: a systematic review and meta-analysis. Ann Rheum Dis. 2007;66(4):433-439.

8. Forbes GB. Lean body mass-body fat interrelationships in humans. Nutr Rev. 1987;45(8):225-231.
9. Toda Y, Segal N, Toda T, Kato A, Toda F. A decline in lower extremity lean body mass per body weight is characteristic of women with early phase osteoarthritis of the knee. $J$ Rheumatol. 2000;27(10):2449-2454.

10. Lee SJ, Hwang SC, Park JM, Kim BT. Perfusion study for internal carotid artery trapping of a traumatic pseudoaneurysm in an unconscious patient. Korean J Neurotrauma. 2015;11(2):170-174.

11. Weiss EP, Racette SB, Villareal DT, et al. Lower extremity muscle size and strength and aerobic capacity decrease with caloric restriction but not with exercise-induced weight loss. J Appl Physiol. 2007; 102(2):634-640.

12. Wang X, Miller GD, Messier SP, Nicklas BJ. Knee strength maintained despite loss of lean body mass during weight loss in older obese adults with knee osteoarthritis. J Gerontol A Biol Sci Med Sci. 2007; 62(8):866-871.

13. Henriksen M, Christensen R, Danneskiold-Samsøe B, Bliddal H. Changes in lower extremity muscle mass and muscle strength after weight loss in obese patients with knee osteoarthritis: a prospective cohort study. Arthritis Rheum. 2012;64(2):438-442.

14. Matsuzawa Y. New criteria for 'obesity disease' in Japan. Circ J. 2002;66(11):987-992.

15. Oh S, Shida T, Yamagishi K, et al. Moderate to vigorous physical activity volume is an important factor for managing nonalcoholic fatty liver disease: a retrospective study. Hepatology. 2015;61(4):1205-1215.

16. Visser M, Fuerst T, Lang T, et al. Validity of fan-beam dual-energy X-ray absorptiometry for measuring fat-free mass and leg muscle mass. J Appl Physiol. 1999;87(4):1513-1520.

17. Sanada K, Miyachi M, Tanimoto M, et al. A cross-sectional study of sarcopenia in Japanese men and women: reference values and association with cardiovascular risk factors. Eur J Appl Physiol. 2010;110(1):57-65.

18. Kelly TL, Wilson KE, Heymsfield SB. Dual energy X-Ray absorptiometry body composition reference values from NHANES. PLoS One. 2009;4(9):e7038.

19. Heymsfield SB, Gallagher D, Mayer L, Beetsch J, Pietrobelli A. Scaling of human body composition to stature: new insights into body mass index. Am J Clin Nutr. 2007;86(1):82-91.

20. Kim B, Tsujimoto T, So R, et al. Weight loss may be a better approach for managing musculoskeletal conditions than increasing muscle mass and strength. J Phys Ther Sci. 2015;27(12):3787-3791.

21. Shinkai S, Kumagai S, Fujihara Y, et al. Predictors for the onset of functional decline among initially non-disabled older people living in a community during a 6-year follow-up. Geriatr Gerontol Int. 2003; 3(S1):S31-S39.

22. Harris T. Muscle mass and strength: relation to function in population studies. J Nutr. 1997;127(5):1004S-1006S.

23. Duché P, Ducher G, Lazzer S, Doré E, Tailhardat M, Bedu M. Peak power in obese and nonobese adolescents: effects of gender and braking force. Med Sci Sports Exerc. 2002;34(12):2072-2078.

24. Hulens M, Vansant G, Lysens R, Claessens AL, Muls E, Brumagne S. Study of differences in peripheral muscle strength of lean versus obese women: an allometric approach. Int J Obes Relat Metab Disord. 2001; 25(5):676-681.

25. Hulens M, Vansant G, Lysens R, Claessens AL, Muls E. Assessment of isokinetic muscle strength in women who are obese. J Orthop Sports Phys Ther. 2002;32(7):347-356.

26. Hughes VA, Frontera WR, Wood M, et al. Longitudinal muscle strength changes in older adults: influence of muscle mass, physical activity, and health. J Gerontol A Biol Sci Med Sci. 2001;56(5):B209-B217.

27. Kim B, Tsujimoto T, So R, Tanaka K. Changes in lower extremity muscle mass and muscle strength after weight loss in obese men: a prospective study. Obes Res Clin Pract. 2015;9(4):365-373.

28. Barbat-Artigas S, Rolland Y, Zamboni M, Aubertin-Leheudre M. How to assess functional status: a new muscle quality index. $J$ Nutr Health Aging. 2012;16(1):67-77.

29. Ploutz-Snyder LL, Manini T, Ploutz-Snyder RJ, Wolf DA. Functionally relevant thresholds of quadriceps femoris strength. J Gerontol A Biol Sci Med Sci. 2002;57(4):B144-B152. 
30. Chomentowski P, Dube JJ, Amati F, et al. Moderate exercise attenuates the loss of skeletal muscle mass that occurs with intentional caloric restriction-induced weight loss in older, overweight to obese adults. J Gerontol A Biol Sci Med Sci. 2009;64(5):575-580.

31. Yoshimura E, Kumahara H, Tobina T, et al. Aerobic exercise attenuates the loss of skeletal muscle during energy restriction in adults with visceral adiposity. Obes Facts. 2014;7(1):26-35.

32. Bliddal H, Christensen R. The management of osteoarthritis in the obese patient: practical considerations and guidelines for therapy. Obes Rev. 2006;7(4):323-331
33. Hunter DJ, Felson DT. Osteoarthritis. BMJ. 2006;332(7542):639-642.

34. Doherty TJ. Invited review: aging and sarcopenia. J Appl Physiol. 2003; 95(4):1717-1727.

35. Doherty TJ. The influence of aging and sex on skeletal muscle mass and strength. Curr Opin Clin Nutr Metab Care. 2001;4(6): 503-508.

36. Goodpaster BH, Park SW, Harris TB, et al. The loss of skeletal muscle strength, mass, and quality in older adults: the health, aging and body composition study. J Gerontol A Biol Sci Med Sci. 2006;61(10): 1059-1064.
Diabetes, Metabolic Syndrome and Obesity: Targets and Therapy is an international, peer-reviewed open-access journal committed to the rapid publication of the latest laboratory and clinical findings in the fields of diabetes, metabolic syndrome and obesity research. Original research, review, case reports, hypothesis formation, expert opinion and commentaries are all considered for publication. The manuscript management system is completely online and includes a very quick and fair peer-review system, which is all easy to use. Visit http://www.dovepress.com/testimonials.php to read real quotes from published authors.

Submit your manuscript here: https://www.dovepress.com/diabetes-metabolic-syndrome-and-obesity-targets-and-therapy-journal 